The International Journal of Indian Psychology

ISSN 2348-5396 (e) | ISSN: 2349-3429 (p)

Volume 5, Issue 1, DIP: 18.01.107/20170501

DOI: $10.25215 / 0501.107$

http://www.ijip.in | October-December, 2017

Research Article

\title{
Spiritual Beliefs Add To the Perceived Health of Cancer Patients
}

\author{
Devakinandan Sharma ${ }^{1}$, Gyanesh Kumar Tiwari ${ }^{2}$, P. K. Rai ${ }^{3}$
}

\section{ABSTRACT}

The study aimed to examine the impacts of spiritual beliefs of diagnosed cancer patients and normal healthy participants on their perceived health. The present research employed a correlational research design to collect and analyze data. The purposive sampling method was used to select the participants in the study. Sixty diagnosed male $(M=52.32, \mathrm{SD}=10.52)$ and female $(M=51.68, S D=6.90)$ cancer patients and 60 normal healthy male $(M=44.00$, $\mathrm{SD}=10.45)$ and female $(\mathrm{M}=47.15, \mathrm{SD}=11.32)$ participants constituted the samples for the study. The findings of the study evinced that spiritual beliefs had important role in shaping the nature and extent of the perceived health of the cancer patients and normal healthy participants. The gender has also been observed to play pivotal role in impacting the perceived health of the participants. It was also observed that spiritual beliefs had shown positive correlations with the scores of perceived health of the male, female and all the cancer patients and normal healthy participants. An important finding of the study denoted that spiritual beliefs contributed significantly and even higher in degree to the scores of the perceived health of the participants inflicted with cancer as compared to the participants with no known history of chronic diseases. In essence, the findings of the study corroborated the important role of spiritual beliefs in determining the perceived health of the participants suffering from fatal disease like cancer. The findings of the study have significant implications in understanding the spiritual beliefs and perceived health of the patients inflicted with fatal diseases and it will benefit equally health professional, care-givers and public at large. The limitations and future directions for future researchers have been discussed at the end.

Keywords: Spiritual beliefs, Perceived Health, Cancer Patients, Health

Researchers greatly differ in their meaning of spirituality (Cobb et al., 2012; Koenig \& Saris, 2012) which have resulted into a broad range of definitions (McCarroll et al., 2005). These

\footnotetext{
${ }^{1}$ Research Scholar, Department of Psychology, School of Humanities \& Social Sciences, Doctor Harisingh Gour Central University, Sagar, 470003, Madhya Pradesh, India

${ }^{2}$ Assistant Professor, Department of Psychology, School of Humanities \& Social Sciences, Doctor Harisingh Gour Central University, Sagar, 470003, Madhya Pradesh, India

${ }^{3}$ Professor, Department of Psychology, School of Humanities \& Social Sciences, Doctor Harisingh Gour Central University, Sagar, 470003, Madhya Pradesh, India

*Responding Author

(C) 2017 Sharma D N , Tiwari G K \& Rai P K; licensee IJIP. This is an Open Access Research distributed under the terms of the Creative Commons Attribution License (www.creativecommons.org/licenses/by/2.0), which permits unrestricted use, distribution, and reproduction in any Medium, provided the original work is properly cited.
} 


\section{Spiritual Beliefs Add To the Perceived Health of Cancer Patients}

definitions span from uni-dimensional which conceives it as a personal belief in a supernatural realm (Schuurmans-Stekhoven, 2014) to broader concepts conveying a quest for an ultimate or sacred meaning (Snyder \& Lopez, 2007) transcending the base and/or material aspects of life. According to McCarroll et al. (2005), the definitions of spirituality can be categorized into twenty-seven categories. These differences about the very nature of spirituality lead to difficulty in studying this scientifically and systematically as multitude of meanings of spirituality impede both understanding and communicate findings among researchers. It has been reported that many attributes of spirituality are key components of ethical living.

The traditional meaning of spirituality denotes it as a process of reformation with the goal to recover the original shape of man and the image of God (Waaijman, 2002). Modern definitions of spirituality emphasize on the subjective experience and the deepest values and meanings by which people live incorporating personal growth or transformation, usually in a context separate from organized religious institutions (Griffin 1988; Sheldrake 2007). Houtman and Aupers (2007) have argued that modern spirituality is a blend of humanistic psychology, mystical, esoteric traditions and eastern religions (Houtman et al., 2007). It has its origin in philosophical, social, or political movements including liberalism, feminist theology and green politics (Snyder \& Lopez, 2007). The researchers have found spirituality to be closely associated with mental health, substance abuse, marital functioning, parenting, and coping as well as a host of indices of human functioning and performance (Cobb et al., 2012; Koenig, 2012).

It has been argued that spirituality is closely linked to physical, mental, emotional, and social aspects of human existence and plays an important role in understanding intrapersonal and interpersonal relations, to deepen relations, to understand human aspect to join nature and environment, to move towards the best and to face the truth in life (Snyder \& Lopez, 2007). Researchers have posited that spirituality goes beyond religious affiliations and denotes universal and unique experience comprising innate and dynamic energy carrying positive emotions.

Spirituality facilitates to develop understanding of self, social relations and helps to understand the intricacies of the legalities of life. These attributes of spirituality significantly impact various outcomes of life including health (Abeles et al., 1999). According to Abeles et al. (1999), it entails daily spiritual experience, meaning, values, belief, forgiveness, private religious practices, religious/spiritual coping, religious support, religious/spiritual history, commitment, organizational religiousness and religious preferences. As spirituality pertains to a kind of positive force, energy or vitality connected to natural goodness and wisdom of human beings, it carries a unique strength in regulating, promoting and consolidating human health, well-being and performance and paves the way for human flourishing. The findings of previous researchers have shown that spirituality acts as a motivational drive that propels people to create a broad sense of personal meaning and contributes significantly to improve 


\section{Spiritual Beliefs Add To the Perceived Health of Cancer Patients}

quality of life, health behaviours and instills strengths to face life threatening illness and to provide solutions to various life problems.

It has been reported that spiritual beliefs facilitate the development of self-consciousness and cultivation of one's own inner resources through personal efforts and personal choice. Many arguments have been put forth by which spiritual beliefs facilitates human performance and well-being. La Pierre (1994) has argued that it involves search for meaning in life, cultivates transcendence, a sense of community and involves the individuals to search for the ultimate truth and leads to personal transformation. It has been found that spirituality promotes health behaviours and life style that enhance positive health outcomes and decreases the risk of disease, reduces stress and improves coping (Levin, Larson, \& Puchalski, 1997). The recognition of the importance of spirituality has led the researchers to include it as an essential ingredient of health and accordingly the definition of health has been proposed which refers to a state of well-being with physical, cultural, psychosocial, economic and spiritual attributes, not simply the absence of an illness.

It was revealed in a survey that patients generally feel comfortable when their physicians talk about religious or spiritual beliefs with them (King \& Bushwick, 1994). It necessitates that the health professional must take care of spiritual needs of their patients to facilitate the process of healing and recovery of the various mental and physical health problems (Hebert, et al., 2001; Koenig, 2002). In the case of fatal disease like cancer, it has been found that understanding spiritual beliefs of the patients is very effective (Norum et al., 2000; Zwingmann et al., 2006).

In spite of the importance of spirituality and spiritual beliefs in health outcomes, health professionals worldwide do not have sufficient exposure to attend the spiritual issues in health care settings. A small beginning in developed countries has been stated recently with the emphasis on cultural sensitivity and holistic patient care (Puchalski \& Larson, 1998) with this recognition that spiritual and religious beliefs provide resources for coping with illness (Johnston \& Spilka, 1991; Pargament, 1997) and provide strengths to modify diagnosis (Ferrell et al., 1992; Reed, 1992). These efforts have confined to understand spiritual health related processes and outcomes including quality of life. Little attention has been paid to understand the role of spirituality and spiritual beliefs in life-threatening illnesses like cancer (Cella et al., 1993).

Recognizing the important role of spirituality in regulating health outcomes (Gallup \& Castelli, 1989; Pargament, 1997), there is a strong need to understand the relationship between spirituality and chronic disease in India also. It is also important to observe that spirituality has been reported to be associated with cognitive, social, affective and emotional phenomena which constitute the core of modern psychology (Hill et al., 2000). The spirituality helps people to deal with the problem of personal lack of control by directing to a set of frameworks and beliefs that extend beyond the self alone in order to find answers to important questions and gives a sense of meaning and purpose also in extreme life situations. 


\section{Spiritual Beliefs Add To the Perceived Health of Cancer Patients}

In this backdrop, the present research attempted to assess the contributions of spiritual beliefs in the perceived health of diagnosed patients with cancer and normal healthy participants. The study attempted to understand difference in perceived health of cancer patients and normal health participants. The study also aimed at assessing the contributions of spiritual beliefs of the cancer patients and normal healthy participants in their perceived health. In addition, it was also aimed to understand the gender differences on these measures.

\section{Hypotheses}

Following hypotheses were framed to be tested through the data of the present study:-

1. The normal healthy participants would show higher mean score on perceived health as compared to the diagnosed cancer patients,

2. The cancer patients will show higher mean scores on the spiritual beliefs as compared to the normal healthy participants.

3. There will be positive correlations among the scores of spiritual beliefs and perceived health of male and female participants.

4. The spiritual beliefs will account for significant variance in the scores of perceived health of male and female cancer patients as well as normal healthy participants.

\section{METHODOLOGY}

\section{Population and Sample}

The present research employed a correlational research design to collect and analyze data. The purposive sampling method was used to select the participants in the study. Sixty diagnosed male $(\mathrm{M}=52.32, \mathrm{SD}=10.52)$ and female $(\mathrm{M}=51.68, \mathrm{SD}=6.90)$ cancer patients age ranging from 36 years to 69 years from Bundelkhand Medical College, Sagar, Madhya Pradesh, India and 60 normal healthy male $(M=44.00, S D=10.45)$ and female $(M=47.15$, $\mathrm{SD}=11.32$ ) participants age spanning from 27 years to 65 years visiting to the various physicians of Sagar city constituted the samples for the present study.

\section{Inclusion and Exclusion Criteria}

Only those patients were included in the study who were diagnosed cancer for at least six months before the start of the study with no known other chronic diseases. On the other hand, only those participants were included as normal healthy participants who did not report any serious diseases at the time of the start of the study.

\section{Tools}

Following psychometric tools were used in the study:

\section{Brief multidimensional measure of religiousness/spirituality (BMMRS)}

Brief multidimensional measure of religiousness/spirituality (BMMRS) was used to measure spirituality of the participants which carries five sub-scales. Daily spiritual experience subscale measured the participants' connection with a higher power in their daily life for example, "I feel the presence of a higher power." This subscale consists of 6 items to be rated on a 6-point scale ranging from 1 (many times a day) to 6 (never). The internal consistency reliability of the subscale (Cronbach's Alpha) was 0.75 . 


\section{Spiritual Beliefs Add To the Perceived Health of Cancer Patients}

Meaning subscale measured their sense of meaning in life for example, "The events in my life unfold according to a divine or greater plan.” This subscale composed of 2 items with a 4-point response format, ranging from 1 (strongly agree) to 4 (strongly disagree). The internal consistency of the subscale was 0.30 . The Values/Beliefs subscale measured religious values and beliefs of the participants for example, "I feel a deep sense of responsibility for reducing pain and suffering in the world." This subscale composed of 2 items with a 4-point response format ranging from 1 (strongly agree) to 4 (strongly disagree). The internal consistency reliability was 0.10 . These two subscales were not employed to collect data due to their low reliability coefficients.

The Forgiveness subscale assessed the degree to which the participants forgave themselves and others and exhibited their belief in the forgiveness of a higher power for example, "I have forgiven those who hurt me." The sub-scale consisted of 3 items rated on a 4-point response format ranging from 1 (always) to 4 (never). The internal consistency reliability was 0.77 . The Religious/Spiritual Coping subscale measured religious and spiritual coping strategies of the participants for example, "I work together with a higher power as partners.” This subscale consisted of 7 items with a 4-point response format, ranging from 1 (a great deal) to 4 (not at all) with the internal consistency reliability of 0.78 .

\section{SF-36 Physical and Mental Health Summary Scale}

The SF-36 Physical and Mental Health Summary Scale was employed to measure eight dimensions of self-perceived health of the participants. The scale assessed the participants' perceptions of themselves as healthy versus sick, with expectations for improving or declining health. It comprised of 36 items with a 5-point response format which ranged from 1 (definitely true) to 5 (definitely false). The internal consistency reliability was 0.78 .

\section{Procedure}

After the approval of the ethical committee of the department of psychology and permissions collected from the competent authority of Bundelkhand Medical College, 60 patients diagnosed with cancer for at least for six months were debriefed about the basic goals of the study and were requested for their written consent to take part in the study. In addition, sixty normal healthy participants with no known history of severe diseases were also consulted and requested to give their consent to be part of the study. After collecting their consents, a set of questionnaires were administered to each participant that took about 20-30 minutes to answer the items. They were made clear that their participation in the study was voluntary and they can withdraw themselves from the study at any given point of time. Following the above arrangement, the data were collected and arranged in order to be analyzed by using mean, standard deviation (SD), coefficient of correlation and regression analysis with the help of SPSS.

\section{RESULTS}

The results of the present study showed that male $(\mathrm{M}=51.60, \mathrm{SD}=2.66)$ cancer participants scored significantly higher mean score $(\mathrm{t}=20.96$, $\mathrm{df}=58, p=.000)$ on spiritual beliefs as 


\section{Spiritual Beliefs Add To the Perceived Health of Cancer Patients}

compared to their female counterparts $(\mathrm{M}=35.00$, $\mathrm{SD}=3.48)$. Likewise, the normal healthy male participants $(\mathrm{M}=49.34, \mathrm{SD}=2.70)$ also exhibited significantly higher mean score $(\mathrm{t}=$ 64.49, $\mathrm{df}=58, p=.000)$ on this measure as compared to the female participants $(\mathrm{M}=35.85$, $\mathrm{SD}=4.64)$. In addition, the female cancer participants $(\mathrm{M}=93.32, \mathrm{SD}=6.12)$ showed significantly higher mean score $(\mathrm{t}=5.86 \mathrm{df}=58, p=.000)$ on perceived health as compared to the male cancer participants $(M=1.02, S D=5.70)$. Conversely, no significant difference $(\mathrm{t}$ $=0, \mathrm{df}=58, p=1)$ was observed in the mean scores of male $(\mathrm{M}=97.90, \mathrm{SD}=6.23)$ and female $(M=97.90, S D=5.71)$ participants having normal health.

The results have demonstrated that cancer patients have achieved significantly higher mean score on spiritual beliefs (Mean $=51.52$, $\mathrm{SD}=2.69$ ) as compared to their normal healthy counterparts (Mean $=36.05$, $\mathrm{SD}=4.49)$ with a statistically significant $\mathrm{t}$-value $(\mathrm{t}=22.94$, $\mathrm{df}=$ $118, p=.000)$. On the other hand, the cancer patients exhibited lower mean score (Mean = 91.82, SD $=9.56$ ) on perceived health as compared to the normal healthy participants (Mean $=99.73, \mathrm{SD}=6.46)$. The difference in their mean score evoked a statistically reliable t-value $(\mathrm{t}=5.32, \mathrm{df}=118, p=.000)$.

The coefficients of correlation among the scores of spiritual beliefs and perceived health of the male and female participants were computed. The results indicated that there were positive non-significant correlations among the scores of spiritual beliefs and perceived health of the males $(\mathrm{r}=.124, p=.478)$ and females $(\mathrm{r}=-.098, p=.642)$ cancer patients. Similarly, the results also indicated that there were positive but non-significant correlations among the scores of spiritual beliefs and perceived health of the normal healthy male $(\mathrm{r}=$ $.181, p=.298)$ and female participants $(\mathrm{r}=.141, p=.553)$. The results showed that spiritual belief contributed $11.60 \%$ to the perceived health $\left(\mathrm{R}^{2}=.116, \mathrm{~F}(1,59)=4.33, p=.045\right)$ of the all the cancer patients. Conversely, the results showed that spiritual belief did not contribute to the perceived health of the all the normal healthy participants.

\section{DISCUSSION}

The findings of the study evinced that spiritual beliefs had important role to shape the nature and extent of the perceived health of the cancer patients and normal healthy participants. The gender has also been observed to play pivotal role in impacting the perceived health of the participants. It was also observed that spiritual beliefs had shown positive correlations with the scores of perceived health of the male, female and all the cancer patients and normal healthy participants. An important finding of the study denoted that spiritual beliefs contributed significantly and even higher in degree of the perceived health of the participants inflicted with cancer as compared to the participants with no known history of chronic diseases.

The researchers have studied extensively about the role of spirituality in physical and mental health. It has been argued that the basic mechanisms through which spirituality impacts health and health outcomes comprise of coping styles, locus of control, social support and social networks, physiological mechanisms, and architecture and the built environment. The 


\section{Spiritual Beliefs Add To the Perceived Health of Cancer Patients}

findings of previous studies demonstrated that a collaborative approach to religious coping leads to enhance mental health which involves the individuals collaborate with God in coping with stress. In the same way, perceiving negative events as externally caused and positive events as internally caused denote an optimistic attribution style that lead to better mental health. It also allows the individuals to reframe or reinterpret events that are seen as uncontrollable.

Pollner (1989) has argued that a person's relationship with a divine or imagined 'Other' can have a major impact on their coping abilities. Spiritual coping includes collaborative, deferring and self-directing styles (Pargament et al., 2000; Pargament et al., 2001). The collaborative style refers to a collaboration of an individual with God when problems arise whereas in deferring approach the individuals take a passive role in the resolution of problems. The self-directing person assumes full responsibility for their problem-solving and is theoretically based on the belief that God has provided or will provide the skills necessary for successful coping (Fabricatore et al., 2004). It has been reported that that the collaborative religious approach to coping is typically helpful and beneficial for health, whereas deferring and self-directing styles have yielded mixed results (Fabricatore et al., 2004).

Locus of control/attribution refers to the way an individual interprets and gives meaning to events or experiences. The attributions for events have been considered important mediators of health. Perceiving negative events as externally caused and positive events as internally caused is widely regarded as an optimistic attribution style and is generally associated with better mental health, in comparison to individuals with the opposite attribution style (Seybold, \& Hill, 2001). Similarly, the individuals with internal locus of control believe that they have some power over a given outcome is usually associated with better mental health than an external locus of control (Peterson, Schwartz, \& Seligman, 1981).

The individuals derive social support from many sources from spiritual arrangements which act as the mediators between spirituality and mental health (Hill, \& Pargament, 2003). These supports are valuable sources of self-esteem, information and companionship that enable people to cope with stress and negative life events or exert its own main effects (Cohen, \& Wills, 1985). According to Loewenthal (1995), these include protecting people from social isolation providing and strengthening family and social networks, a sense of belonging and self-esteem, and offering spiritual support in times of adversity. Hill and Pargament (2003) argued that members of other social networks may be fluid or transitory, whereas support gathered from a religious or spiritual network can accompany an individual from birth to death.

Certain expressions or elements of spirituality may positively affect various physiological mechanisms involved in health (Seybold, \& Hill, 2001). Emotions encouraged in many spiritual traditions, including hope, contentment, love and forgiveness, may serve the individual by affecting the neural pathways that connect to the endocrine and immune systems (Seybold, \& Hill, 2001). Negative emotions that are actively discouraged in many 
religions like anger or fear trigger the release of the neurotransmitter norepinephrine and the endocrine hormone cortisol which inhibit the immune system, increase risk of infection, elevate blood pressure and increase risk of stroke and cardiovascular disease. Architecture and the built environment of the spiritual system may mediate the relationship between spirituality and mental health. Many people find spiritual expression in the significance of specific spiritual buildings and architecture, such as churches, temples or mosques. This has long been expressed through art, nature and music, all of which can be important vehicles of spirituality for many people. This sense of connectedness to other people, to oneself or to God may be an important factor that underpins many expressions of spirituality (Meis, 1991).

In addition, spirituality in health is important for other reasons also. They involve the way people understand health, illness, diagnoses, recovery and loss (D'Souza, 2007), the strategies they use to cope with illness, their resilience, resources and sense of support (Eckersley, 2007), decision-making about treatment, medicine and self-care (Rumbold, 2007), people's expectations of and relationship with health service providers (Koslander, \& Arvidsson, 2007), day to day health practices and lifestyle choices (Larson, \& Larson, 2003), and overall health outcomes (Koenig, 2007). In this background of the findings of previous researches, the findings of the present study can be justified and explained.

A study by Hammermeister et al. (2005) involved a survey of spirituality and gender, the findings demonstrated that the women participants exhibited higher mean score as compared to their male counterparts. It has been argued that gender differences in spirituality are caused by differences in religious thinking of male and female (Belenky et al., 1986). According to these researchers, the religious thinking is of two types. First is connected with knowing whereas the second denotes separate knowing. The first category involves thinking which helps to understand relationships, feelings and other people that is more frequently observed in women. On the other hand, separate thinking style causes to reduce the personal feelings and carries ethical fairness and is exhibited by more by the males as compared to the females. It has also been reported that woman visits more religious places than men and found to be involved more in prayers and religious practice than men. Another research reported that there is a difference between men and women at the level of spiritualism because they perceive and express differently (Thompson \& Remmes, 2002).

The findings of the present study convey contradictory results regarding gender differences in spirituality. Here, the spiritual level of the male participants was found higher as compared to their female counterparts. The reason behind this finding may be due to gender differences in their cognitive abilities. As spirituality conveys a logical conception of the spiritual phenomenon, the gender difference of this sort can be explainable. Ardila et al. (2011) has reported three cognitive abilities carried by the males and females. The first denotes verbal abilities on which women do better than men. The second is spatial abilities on which males do better than females. Lastly, arithmetical abilities also go in favour of the males. The gender differences in these abilities may be acting behind this difference in the spiritual beliefs of the male and female participants (Halpern \& Collaer, 2005). 


\section{Spiritual Beliefs Add To the Perceived Health of Cancer Patients}

It has also been reported that the experience of spirituality and religiosity is different in men and women (Maselko \& Kubzansky, 2006). The male and female also differ in their outcomes of having spiritual beliefs. The public religions activity impacts positively their health and well-being of the males whereas public religious activities and spiritual experiences have close associations with the health and well-being of the females. Although, researchers report that women are more religious than men. This difference in the religiosity of women may be due to the differences in their socialization, frequent visits of the religious places, emotional structuring and motivational affiliations to religious matters. But all that is practiced also impacts the spirituality and religiosity of men. This might be the reason behind higher spiritual belief scores of the male participants as compared to their female counterparts in this study. The hypotheses framed to be tested through the finding of the present study got partially approved. The first hypothesis inferred that the normal healthy participants would show higher mean score on perceived health as compared to the diagnosed cancer patients whereas the second hypothesis expected that the cancer patients will show higher mean scores on the spiritual beliefs as compared to normal healthy participants. The third hypothesis conjectured that there will be positive correlations among the scores of spiritual beliefs and perceived health of male and female participants. The fourth hypothesis expected that the spiritual beliefs will account for significant variance in the scores of perceived health of male and female cancer patients as well as normal healthy participants.

\section{SUMMARY AND CONCLUSIONS}

The major conclusion of the study is that the spiritual beliefs and gender had important role in the perceived health of the cancer patients and normal healthy participants. The findings of the study suggested that spiritual beliefs had positive correlations with the scores of perceived health of the male, female and all the cancer patients and normal healthy participants. Lastly, spiritual beliefs contributed significantly and even higher in degree of the perceived health of the participants inflicted with cancer as compared to the participants with no known history of chronic diseases. This constituted an important finding of the study. Use of limited variables, only use of quantitative methods and small sample size were some of the important limitations of the study.

\section{DIRECTIONS FOR FUTURE RESEARCHERS}

The researchers have reported that there are many contributors to the perceived health of the individuals. Perceived health is not only determined by having a particular spiritual belief but it is equally shaped by self-compassion (Verma \& Tiwari, 2017a), personality attributes (Verma \& Tiwari, 2017b), self-concept (Gujare \& Tiwari, 2016a; Gujare \& Tiwari, 2016b), emotional intelligence (Tiwari, 2016a), self-forgiveness (Mudgal \& Tiwari, 2017). Positive psychological outcomes and constructs like Yogic practices (Tiwari, 2016b), positive body image (Jain, \& Tiwari, 2016a; Jain, \& Tiwari, 2016b; Tiwari, \& Kumar, 2015; Tiwari, 2014), emotion regulation (Tiwari, 2015), self-forgiveness, meta-cognitive awareness (Jain, Tiwari \& Awasthi, 2017) and life satisfaction (Mudgal, \& Tiwari, 2015) contribute to life outcomes which, in turn, impact human performance and functioning including spiritual beliefs and perceived health. Future researchers may involve many variables like these to develop deeper 


\section{Spiritual Beliefs Add To the Perceived Health of Cancer Patients}

understanding into the nature and dynamics of spiritual beliefs and perceived health. In addition, future researchers may develop deeper understanding into these constructs by employing qualitative methods and mixed methods designs which carry in depth data with varied meanings.

\section{Acknowledgments}

The author appreciates all those who participated in the study and helped to facilitate the research process.

\section{Conflict of Interest}

There is no conflict of interest of the authors with anyone regarding financial matters.

\section{REFERENCES}

Abeles et al. (1999). Multidimensional Measurement of Religiousness/Spirituality for Use in Health Research. Fetzer Institute \& National Institute on Aging Working Group Kalamazoo, MI

Ardila, A., Rosselli, M., Matute, E., \& Inozemtseva, O. (2011). Gender differences in cognitive development. Developmental psychology, 47(4), 984.

Belenky, M. F., Clinchy, B. M., Goldberger, N. R., \& Tarule, J. M. (1986). Women's ways of knowing: The development of self, voice, and mind (Vol. 15). New York: Basic books.

Cella et al. (1993). The Functional Assessment of Cancer Therapy Scale: Development and validation of the general measure. Journal of Clinical Oncology, 11, 570-579

Cobb, M., Puchalski, C. M., \& Rumbold, B. (Eds.). (2012). Oxford textbook of spirituality in healthcare. Oxford University Press.

Cohen, S., \& Wills, T. A. (1985). Stress, social support, and the buffering hypothesis: Psychological Bulletin, 98(2), 310-357.

D'Souza, R. (2007). The Importance of Spirituality in Medicine and its application to Clinical Practice. Medical Journal of Australia, 186(10), 57-59.

Eckersley, R. (2007). 'Culture, Religion, Spirituality and Health: looking at the big picture', Medical Journal of Australia, 186(10), 54-56.

Fabricatore, A. N., Handal, P. J., Rubio, D. M. \& Gilner, F. H. (2004). Stress, Religion, and Mental Health: Religious Coping in Mediating and Moderating Roles. International Journal for the Psychology of Religion, 14(2), 91-108.

Ferrell, B., Grant, M., Schmidt, G. M., Rhiner, M., Whitehead, C., Fonbuena, P., \& Forman, S. J. (1992). The meaning of quality of life for bone marrow transplant survivors Part 1. The impact of bone marrow transplant on quality of life. Cancer nursing, 15(3), 153-160.

Gallup, G., Jr., \& Castelli, J. (1989). The people’s religion: American faith in the 90’s. New York, NY: MacMillan Publishing Company.

Griffin, D. R. (Ed.) (1988). Spirituality and society: Postmodern visions. Albany: State university of New York Press.

Gujare, S. K. \& Tiwari, G. K. (2016a). Mental health symptoms predict academic achievement of the female students. The International Journal of Indian Psychology, Volume 4, Issue 1, No.76, 93-111. 


\section{Spiritual Beliefs Add To the Perceived Health of Cancer Patients}

Gujare, S. K. \& Tiwari, G. K. (2016b). Academic self-concept and academic outcome of the graduate students: The mediating role of socioeconomic status and gender. International Journal of Education and Psychological Research, Volume 4, Issue 5, 17.

Halpern, D. F., \& Collaer, M. (2005). Sex differences in visuospatial abilities: More than meets the eye. In: Shah P, Miyake A, editors. Higher-level visuospatial thinking and cognition. Cambridge, MA: Cambridge University Press.

Hammermeister, J., Flint, M., El-Alayli, A., Ridnour, H., \& Peterson, M. (2005). Gender differences in spiritual well-being: Are females more spiritually-well than males? American Journal of Health Studies, 20(2), 80-84.

Hebert, R. S., Jenckes, M. W., Ford, D. E., O'connor, D. R., \& Cooper, L. A. (2001). Patient Perspectives on Spirituality and the Patient-physician Relationship. Journal of general internal medicine, 16(10), 685-692.

Hill et al. (2000). Conceptualizing religion and spirituality: points of commonality, points of departure. J. Theory Soc. Behav., 30, 51-77

Hill, P. C., \& Pargament, K. I. (2003). Advances in the conceptualization and measurement of religion and spirituality. Implications for physical and mental health research: American Psychologist, 58(1), 64-74.

Houtman, D., \& Aupers, S. (2007). The Spiritual Turn and the Decline of Tradition: The Spread of Post-Christian Spirituality in 14 Western Countries, 1981-2000. Journal for the Scientific Study of religion, 46(3), 305-320.

Jain, D, Tiwari, G. K., \& Awasthi, I. D. (2017). Impact of Metacognitive Awareness on Academic Adjustment and Academic Outcome of the Students. International Journal of Indian Psychology,5(1), 123-138. DOI: 10.25215/0501.034

Jain, P., \& Tiwari, G. K. (2016a). Body image satisfaction and Life Satisfaction in HIV/AIDS patients. The International Journal of Indian Psychology, Volume 3, Issue 2, No.1, 8190.

Jain, P., \& Tiwari, G. K. (2016b). Positive body image and general health: A Mixed Methods Study. The International Journal of Indian Psychology, Volume 4, Issue 1, No. 76, 3351.

Johnston, S. C. \& Spilka, B. (1991). Coping with breast cancer: the roles of the clergy and faith, Journal of Religion and Health, 1, 21-33.

King, D. E., \& Bushwick, B. (1994). Beliefs and attitudes of hospital inpatients about faith healing and prayer. Journal of Family Practice, 39, 349-352.

Koenig, H. (2007). Religion, spirituality and medicine in Australia: research and clinical practice. Medical Journal of Australia, 186(10), 45-50.

Koenig, H. G. (2012). Religion, spirituality, and health: the research and clinical implications. ISRN psychiatry.

Koenig, H. G., \& Saris, G. (2002). Spirituality in patient care: Why, how, when, and what (p. 165). Philadelphia: Templeton Foundation Press.

Koslander, T. \& Arvidsson, B. (2007). 'Patients' conceptions of how the spiritual dimension is addressed in mental health care: a qualitative study', Journal of Advanced Nursing, 57(6), 597-604. 


\section{Spiritual Beliefs Add To the Perceived Health of Cancer Patients}

LaPierre L. (1994) A model for describing spirituality. Journal of Religion and Health 33, 153-161.

Larson, D. \& Larson, S. (2003). 'Spirituality's Potential Relevance to Physical and Emotional Health: A Brief Review of Quantitative Research', Journal of Psychology and Theology, Volume 31.

Levin, J. S., Larson, D., \& Puchalski, C. (1997). 'Religion and spirituality in medicine Research and education'. Journal of the American Medical Association, 278(9), 792793.

Loewenthal, K. M. (1995). Mental Health and Religion: London, Chapman \& Hall.

Maselko, J., \& Kubzansky, L. D. (2006). Gender differences in religious practices, spiritual experiences and health: Results from the US General Social Survey. Social Science \& Medicine, 62, 2848-2860

Masters, K. S. (2013). Brief multidimensional measure of religiousness/spirituality (BMMRS). In Encyclopedia of Behavioral Medicine (pp. 267-269). Springer New York.

McCarroll, P., O’Connor, T., \& Meakes, E. (2005). Assessing plurality in spirituality definitions. Spirituality and health: Multidisciplinary explorations, 43-61.

Meis, J. A. (1991). A haven for the spirit. A well-designed chapel can improve nursing home residents' spiritual and psychological health. Health Prog., 72(5), 56-59.

Mudgal, S., \& Tiwari, G. K. (2015). Self-Forgiveness and Life Satisfaction in People Living with HIV/AIDS. The International Journal of Indian Psychology, Volume 3, Issue 1, No.10, 101-108.

Mudgal, S., \& Tiwari, G. K. (2017). High level of self-forgiveness facilitates quality of life in males and females. Vaichariki-A Multidisciplinary Refereed International Research Journal, 8(3), 154-166.

Norum, J., Risberg, T., \& Solberg, E. (2000). Faith among patients with advanced cancer. A pilot study on patients offered "no more than" palliation. Support Care Cancer, 8, 110-114.

Pargament, K. I. (1997). The psychology of religion and coping: Theory, research, practice. New York, NY: Guilford Press

Pargament, K. I., H Koenig, Tarakeshwar G. N., \& Hahn, J. (2001). Religious struggle as a predictor of mortality among medically ill elderly patients: a 2-year longitudinal study. Arch. Intern. Med., 161(15), 1881-1885.

Pargament, K. I., H. G. Koenig, \& Perez, L. M. (2000). The many methods of religious coping: development and initial validation of the RCOPE: Journal of Clinical Psychology, 56(4), 519-543.

Peterson, C., Schwartz, S. M., \& Seligman, M. E. (1981). Self-blame and depressive symptoms. Journal of Personality and Social Psychology, 41 (2), 253-259.

Pollner, M. (1989). Divine relations, social relations, and well-being. Journal of Health and Social Behaviour, 30, 92-104.

Puchalski, C. M., \& Larson, D. B. (1998). Developing curricula in spirituality and medicine. Academic Medicine, 73(9), 970-4. 
Reed, P. G. (1992). An emerging paradigm for the investigation of spirituality in nursing. Research in Nursing and Health, 15, 349-357.

Rumbold, B. (2007). A Review of Spiritual Assessment in health care practice. Medical Journal of Australia, 186(10), 60-62.

Schuurmans-Stekhoven, J. (2014). Measuring Spirituality as Personal Belief in Supernatural Forces: Is the Character Strength Inventory-Spirituality subscale a brief, reliable and valid measure. Implicit Religion, 17(2), 211-22.

Seybold, K. S., \& Hill, P. C. (2001). The Role of Religion and Spirituality in Mental and Physical Health. Current Directions in Psychological Science, 10(1), 21-24.

Sheldrake, P. (2007). A brief history of spirituality. Oxford: Blackwell Publishing Ltd.

Snyder, C. R. \& Lopez, S. J. (2007). Positive Psychology, Sage Publications, Inc., ISBN 07619-2633-X

Thompson, E. H., Jr., \& Remmes, K. R. (2002). Does masculinity thwart being religious? An examination of older men's religiousness. Journal for the Scientific Study of Religion, 41, 521-532.

Tiwari, G. K. \& Kumar, S. (2015). Psychology and body image: A review. Shodh Prerak, 5, $1-9$.

Tiwari, G. K. (2014). Body image satisfaction enhances self-esteem. Vaichariki-A Multidisciplinary Refereed International Research Journal, IV (4), 7-11.

Tiwari, G. K. (2015). Chronic Physical Illness Affects Emotion Regulation Process: A Case of HIV/AIDS. The International Journal of Indian Psychology, Volume 3, Issue 1, No.8, 158-166.

Tiwari, G. K. (2016a). Mediating role of emotional intelligence in academic achievement of the graduate students. The International Journal of Indian Psychology, Volume 4, Issue 1, No.74, 49-59.

Tiwari, G. K. (2016b). Yoga and mental health: An Underexplored relationship. The International Journal of Indian Psychology, Volume 4, Issue 1, No. 76, $19-31$.

Verma, Y. \& Tiwari, G. K. (2017a). Self-Compassion as the Predictor of Flourishing of the Students. The International Journal of Indian Psychology, Volume 4, Issue 3, 10-29.

Verma, Y. \& Tiwari, G. K. (2017b). Relative dominance of Sattva and Tamas Gunas (qualities) makes a difference in self-compassion and human flourishing. International Journal of Education and Psychological Research, Volume 6, Issue 2, 67-74.

Waaijman, K. (2002), Spirituality: Forms, Foundations, Methods, Peeters Publishers.

Ware, J. E., Kosinski, M., \& Keller, S. K. (1994). SF-36 Physical and Mental Health Summary Scales: A User's Manual. Boston: The Health Institute.

Zwingmann, C., Wirtz, M., Muller, C., Korber, J., \& Murken, S. (2006). Positive and negative religious coping in German breast cancer patients. J Behav Med., 29, 533-47.

How to cite this article: Sharma D N , Tiwari G K \& Rai P K (2017). Spiritual Beliefs Add To the Perceived Health of Cancer Patients. International Journal of Indian Psychology, Vol. 5, (1), DIP: 18.01.107/20170501, DOI: 10.25215/0501.107 